\title{
Differences in Free Volume Elements of the Carrier Matrix Affect the Stability of Microencapsulated Lipophilic Food Ingredients
}

\author{
S. Drusch • K. Rätzke • M. Q. Shaikh • Y. Serfert • \\ H. Steckel • M. Scampicchio • I. Voigt $\cdot$ K. Schwarz • \\ S. Mannino
}

Published online: 16 April 2009

(C) Springer Science + Business Media, LLC 2009

\section{Erratum to: Food Biophysics 4(1):42-48 \\ DOI 10.1007/s11483-008-9100-9}

In the original version of this article, there has been a mistake in sample acronyms in the last sentence of 8th paragraph of "Results and Discussion" section, before the concluding final paragraph (p. 47). The sentence should read:

This might be a reason why a difference in the course of lipid oxidation might occur between e.g. M50 and MD/ G38, which show a similar $\tau_{\text {o-Ps. }}$.

The online version of the original article can be found at http://dx.doi. org/10.1007/s11483-008-9100-9.

S. Drusch $\cdot$ M. Scampicchio $\cdot$ S. Mannino

DISTAM, Università degli Studi di Milan, Milan, Italy

Y. Serfert $\cdot$ K. Schwarz

Institute of Human Nutrition and Food Science,

University of Kiel, Kiel, Germany

K. Rätzke • M. Q. Shaikh

Institute for Materials Science,

Chair for Multicomponent Materials, University of Kiel,

Kiel, Germany

H. Steckel

Pharmaceutical Institute, University of Kiel, Kiel, Germany

I. Voigt

National Starch and Chemical GmbH, Hamburg, Germany

S. Drusch $(\bowtie)$

Dipartimento di Scienze Tecnologie Alimentari

e Microbiologiche, Università degli Studi di Milan, Via Celoria 2,

20133 Milan, Italy

e-mail: stephan.drusch@guest.unimi.it 